\title{
THERMODYNAMIC CHARACTERIZATION OF HUMIC ACID-SURFACTANT INTERACTION: NEW INSIGHTS INTO THE CHARACTERISTICS AND STRUCTURE OF HUMIC ACIDS
}

\author{
Leonardus Vergütz ${ }^{(1)^{*}}$, Luis Henrique Mendes da Silva ${ }^{(2)}$, Roberto Ferreira Novais ${ }^{(1)}$, Maria \\ do Carmo Hespanhol da Silva ${ }^{(2)}$, Aparecida Barbosa Mageste ${ }^{(3)}$ and Ivo Ribeiro Silva ${ }^{(1)}$
}

(1) Universidade Federal de Viçosa, Departamento de Solos, Viçosa, Minas Gerais, Brasil.

(2) Universidade Federal de Viçosa, Departamento de Química, Grupo de Química Verde Coloidal e Macromolecular, Viçosa, Minas Gerais, Brasil.

(3) Universidade Federal de Ouro Preto, Departamento de Química, Campus Universitário Morro do Cruzeiro, Ouro Preto, Minas Gerais, Brasil.

* Corresponding author.

E-mail: leonardus.vergutz@ufv.br

\begin{abstract}
Humic acids (HA) are a component of humic substances (HS), which are found in nearly all soils, sediments, and waters. They play a key role in many, if not most, chemical and physical properties in their environment. Despite the importance of HA, their high complexity makes them a poorly understood system. Therefore, understanding the physicochemical properties and interactions of $\mathrm{HA}$ is crucial for determining their fundamental role and obtaining structural details. Cationic surfactants are known to interact electrostatically and hydrophobically with HA. Because they are a very well-known and characterized system, they offer a good choice as molecular probes for studying HA. The objective of this study was to evaluate the interaction between cationic surfactants and HA through isothermal titration calorimetry in a thermodynamic manner, aiming to obtain information about the basic structure of $\mathrm{HA}$, the nature of this interaction, and if $\mathrm{HA}$ from different origins show different basic structures. Contrary to what the supramolecular model asserts, HA structure is not loosely held, though it may separate depending on the conditions the HA are subjected to in their milieu. It did not show any division or conformational change when interacting with surfactants. The basic structure of the HA remains virtually the same regardless of the different sources and compositions of these HA.
\end{abstract}

Keywords: enthalpy, humic substances, isothermal titration calorimetry, macromolecular structure, microcalorimetry, supramolecular structure. 


\title{
RESUMO: CARACTERIZAÇÃO TERMODINÂMICA DA INTERAÇÃO ÁCIDO HÚMICO-SURFACTANTE. NOVOS DISCERNIMENTOS SOBRE AS CARACTERÍSTICAS E ESTRUTURA DOS ÁCIDOS HÚMICOS
}

\begin{abstract}
Ácidos húmicos (AH) são componentes principais das substâncias húmicas (SH), as quais são encontradas em praticamente todos os solos, sedimentos e corpos d'água. Elas apresentam papel fundamental na maioria, se não todas, as propriedades químicas e físicas do ambiente. Apesar de sua importância, a elevada complexidade dos $\mathrm{AH}$ (e das $\mathrm{SH}$, em geral) fazem deles um sistema pouco compreendido. Portanto, compreender as propriedades físico-químicas e as interações dos AH se faz crucial para determinar o papel fundamental dessas substâncias no ambiente e obter detalhes estruturais. Surfactantes catiônicos são conhecidos por interagirem com AH por interações tanto eletrostáticas (cabeça polar) quanto hidrofóbicas (cauda apolar). Como os surfactantes representam um sistema muito bem conhecido e caracterizado, eles representam ótimas escolhas como sondas moleculares para estudar os AH. Avaliou-se a interação entre surfactantes catiônicos com AH pela técnica de titulação calorimétrica isotérmica visando obter informações sobre a estrutura básica dos AH, a natureza dessa interação e se $A H$ de diferentes origens apresentam estruturas básicas diferentes. Ao contrário do que o modelo supramolecular prega, a estrutura dos AH não é fracamente retida, podendo separar-se dependendo das condições do meio ao que forem submetidas. A estrutura dos AH não sofreu nenhuma divisão ou mudança conformacional durante a interação com os surfactantes catiônicos. Parece existir uma estrutura básica dos AH que é mantida virtualmente a mesma apesar das diferentes origens ou composições desses AH.
\end{abstract}

Palavras-chave: entalpia, substâncias húmicas, titulação calorimétrica isotérmica, estrutura macromolecular, microcalorimetria, estrutura supramolecular.

\section{INTRODUCTION}

Humic acids (HA) are found in nearly all soils, sediments, and natural waters. They are formed by chemical, physical, and biological transformation of plant, animal, and microorganism matter into relatively stable and polydisperse particles. They are generally described as refractory, heterogeneous, and amphiphilic molecules that behave like weak-acid polyelectrolytes and are able to associate with a variety of inorganic and organic substances by electrostatic and, or, hydrophobic interactions (Koopal et al., 2004; Gamboa and Olea, 2006). Therefore, HA play a key role in many, if not most, chemical and physical properties in the environment. Also, HA is a major fraction of humic substances (HS), which makes up the bulk of soil organic matter (SOM) and is very important for the global $\mathrm{C}$ cycle, with twice as much carbon stabilized as SOM than there is in the whole atmosphere (Amundson, 2001).

In spite of the importance of HA, their high heterogeneity and complexity make them a poorly known and understood system (Piccolo, 2001; Roger et al., 2010; Zhang et al., 2011). In the past, HA were believed to be complex alien macromolecules structured as large nets of aromatic groups, which would grant them their well-known recalcitrant characteristic (Kickuth, 1972). Over time, macromolecular models became more aliphatic in nature and the more recent models conceptualize HA structure as supramolecular associations of self-assembling heterogeneous and relatively small molecules. First, the membrane-micelle model was proposed based on the aggregation of humic substances due to their amphiphilic nature (Wershaw, 1993; Wershaw, 1999). Later, evidence appeared that this supramolecular conformation is stabilized predominantly by weak dispersive forces instead of covalent linkages (Piccolo, 2001). After that, based on a series of Nuclear Magnetic Resonance (NMR) experiments, Simpson and his co-workers showed that even though hydrophobic associations, charge interactions, and hydrogen bonds are important for aggregation, metal ions play a crucial role in aggregate formation and stability of humic structures (Simpson et al., 2002). According to this view, a basic structure of HA does not exist, but rather they are complex mixtures of many components, which vary in ratio and structure according to sample origin, extraction procedure, maturity, degree of degradation, depositional environment, and formation processes ( $\mathrm{Lu}$ et al., 2000; Simpson et al., 2002; Peña-Méndez et al., 2007).

Basic information regarding their molecular structure is still lacking, yet understanding HA physicochemical properties and interactions is crucial for understanding their fundamental behavior and obtaining structural details (Kucerík et al., 2004). Like HA, surfactants are amphiphile molecules, showing hydrophilic and hydrophobic moieties. Due to their amphiphilic nature and opposite charges, HA and cationic surfactants easily associate through both electrostatic and hydrophobic interactions (Koopal et al., 2004; Gamboa and Olea, 2006). Therefore, surfactant molecules typify an ideal system to be used as a molecular probe to interact 
with HA and study such a complex system. One way to perform the thermodynamic study of this interaction is through the isothermal titration calorimetry (ITC) technique.

Isothermal titration calorimetry is a technique that combines thermochemical and analytical applications and directly measures the enthalpy change of any molecular interaction as a function of the amount of added reactant. It allows one to monitor the binding process, to determine binding isotherms, and also, in some cases, to give direct information on the structure of the complex (O'Brien et al., 2001; Tam and Wyn-Jones, 2006). The thermodynamic functions determined by ITC (enthalpy change - $\Delta H$; entropy change - $\Delta S$; free Gibbs energy change - $\Delta G$; and calorific capacity - $\mathrm{C}_{p}$ ) are useful for understanding the energetic changes behind any polymer-reactant interaction. The ITC technique is versatile, extremely sensitive, and non-selective with regard to polymers and reactants. The only requirement is for an enthalpy change to be generated during the binding process. Due to its high sensitivity, the ITC technique is also known as microcalorimetry. While the standard enthalpy of formation of one mole of water $(\sim 18 \mathrm{~mL})$ is $-285,800 \mathrm{~J} \mathrm{~mol}^{-1}$, current calorimeters can sense heat changes as low as $0.000000001 \mathrm{~J}(\mathrm{~nJ})$.

We believe that understanding the driving forces associated with HA-surfactant interactions will allow inferences on HA structure, organization, and behavior in the environment. According to the enthalpy changes involved in this interaction, it will be possible to determine the following: the electrostatic and/or hydrophobic character of this interaction, HA charge density, number of layers of surfactant binding onto HA, and the possibility of the HA structure going through any dissociation or conformational changes during its interaction with surfactants. The objective of this study was to evaluate the binding between cationic surfactants and HA under different ionic strengths in a thermodynamic manner, aiming to gather information regarding: basic HA structure; the nature of this interaction; and whether HA from different origins show different basic structures.

\section{MATERIAL AND METHODS}

\section{Material}

Elliott soil humic acid (ESHA), Suwannee River humic acid (SRHA), and Pahokee peat humic acid (PPHA) were purchased from the International Humic Substances Society (IHSS). Cationic surfactant hexadecylpyridinium chloride monohydrate (CPC) was purchased from Sigma-Aldrich. The critical micelle concentration $(\mathrm{cmc})$ value for CPC was $0.11 \pm 0.03 \mathrm{mmol} \mathrm{L}^{-1}$ (Koopal et al., 2004). Humic acid (HA) solutions $\left(0.1 \mathrm{mg} \mathrm{mL}^{-1}\right)$ and surfactant solutions $\left(10.0 \mathrm{mmol} \mathrm{L}^{-1}\right)$ were prepared in a carbonate buffer of $\mathrm{pH} 10\left(6.4 \mathrm{mmol} \mathrm{L}^{-1} \mathrm{Na}_{2} \mathrm{CO}_{3}+6.0 \mathrm{mmol} \mathrm{L}^{-1} \mathrm{NaHCO}_{3}\right)$ (Koopal et al., 2004). HA-surfactant interactions were evaluated in four ionic strengths (IS) $(0.00$, $0.05,0.10$, and $0.30 \mathrm{~mol} \mathrm{~L}^{-1}$ ) and adjusted with $\mathrm{KCl}$ salt. The soil humic acid (ESHA) was evaluated in all four IS, whereas peat humic acid (PPHA) was evaluated in IS $=0.00,0.05$, and $0.10 \mathrm{~mol} \mathrm{~L}^{-1}$, and river humic acid (SRHA) was evaluated only in IS $=0.00 \mathrm{~mol} \mathrm{~L}^{-1}$ (Table 1$)$.

\section{Isothermal Titration Calorimetry (ITC)}

The enthalpy changes of HA-surfactant interactions in four different ionic strengths were performed in triplicate using a CSC-4200 microcalorimeter (Calorimeter Science Corp.) controlled by ItcRun software with a $1.75 \mathrm{~mL}$ reaction cell (sample and reference). The whole calorimetric procedure was chemically and electrically calibrated to the heat of protonation of (tris (hydroxymethyl) aminomethane) and the joule

Table 1. Thermodynamic parameters for humic acid-surfactant interactions at different ionic strengths

\begin{tabular}{|c|c|c|c|c|c|c|}
\hline HA type ${ }^{(1)}$ & IS & cmc & cac & $C_{2}$ & $\Delta H_{\text {agg }}$ (int) & Extent of binding of CPC on HA \\
\hline & $\mathrm{mol} \mathrm{L}^{-1}$ & & $\mathrm{amol} \mathrm{L} \mathrm{L}^{-1}$ & & $\mathrm{~kJ} \mathrm{~mol}{ }^{-1}$ & $\mathrm{mmol} \mathrm{g}^{-1}$ \\
\hline SRHA & 0.00 & 0.1 & 0.055 & 1.25 & -8.65 & 13.78 \\
\hline PPHA & 0.00 & 0.1 & 0.055 & 1.16 & -9.02 & 12.65 \\
\hline ESHA & 0.00 & 0.1 & 0.055 & 1.20 & -8.76 & 13.22 \\
\hline PPHA & 0.05 & 0.1 & 0.055 & 1.25 & -3.64 & 13.78 \\
\hline ESHA & 0.05 & 0.1 & 0.055 & 0.81 & -3.74 & 8.10 \\
\hline PPHA & 0.10 & 0.1 & 0.055 & 1.20 & -1.52 & 13.22 \\
\hline ESHA & 0.10 & 0.1 & 0.055 & 0.85 & -1.84 & 8.67 \\
\hline ESHA & 0.30 & 0.1 & 0.055 & 0.85 & -0.19 & 8.67 \\
\hline
\end{tabular}

(1) SRHA: Suwannee River humic acid; PPHA: Pahokee peat humic acid; ESHA: Elliott soil humic acid; IS: ionic strength; $c m c$ : critical micelle concentration; cac: critical aggregation concentration; $C_{2}$ : HA saturation concentration; $\Delta H_{\text {agg }}($ int): integral enthalpy change due to the aggregation. 
effect, as recommended (Christensen et al., 1976). Deionized water was used to prepare all solutions. Titrations were carried out through step-by-step injections $(5 \mu \mathrm{L})$ of the concentrated surfactant solutions (titrant) with a gas-tight Hamilton syringe $(250 \mu \mathrm{L})$, controlled by the calorimeter, with intervals of $60 \mathrm{~min}$ between each injection. These aliquots of concentrated surfactant solution were injected in the sample cell, where it was stirred at $300 \mathrm{rpm}$, and measurements were carried out at a constant temperature of $25.000 \pm 0.001{ }^{\circ} \mathrm{C}$. A good review of this technique and its fundamentals can be found in Velázquez-Campoy et al. (2004) and Tam and Wyn-Jones (2006).

\section{RESULTS AND DISCUSSION}

An example of the titration curves obtained in this study is shown in figure 1 , where the observed enthalpy changes $\left(\Delta H_{\text {obs }}\right)$ for each injection are plotted against the total surfactant concentration in the sample cell. In a typical experiment, there was an addition of $5 \mu \mathrm{L}$ of surfactant aqueous solution (CPC $\left.10 \mathrm{mmol} \mathrm{L}^{-1}\right)$ to HA solution $\left(0.1 \mathrm{mg} \mathrm{mL}^{-1}\right)$ and to pure carbonate buffer solution.

From the titration of surfactant in pure buffer solution, the following processes produce measurable enthalpy changes: (a) demicellization $\left(\Delta H_{\text {demic }}\right)$ - surfactant is titrated in micellar form and, following the initial titrations, these surfactant micelles dissociate into monomers; (b) dilution

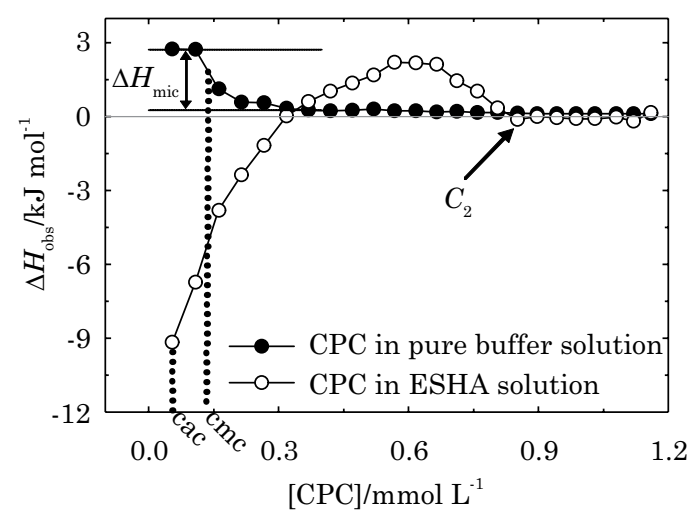

Figure 1. Calorimetric titration curves (observed enthalpy changes $-\Delta H_{\text {obs }}$ ) from the addition of hexadecylpyridinium chloride monohydrate (CPC) surfactant solution $\left(10.0 \mathrm{mmol} \mathrm{L}^{-1}\right)$ to the Elliott soil humic acid (ESHA) solution $\left(0.1 \mathrm{mg} \mathrm{mL} \mathrm{m}^{-1}\right)$ and its dilution in carbonate buffer at $25{ }^{\circ} \mathrm{C}$ and $0.05 \mathrm{~mol} \mathrm{~L}^{-1}$ ionic strength (IS). The acronyms cac, cmc, and $C_{2}$ stand for critical aggregation concentration, critical micelle concentration, and saturation concentration, respectively.
$\left(\Delta H_{\text {dil }}\right)$ - the surfactant monomers are obliged to carry out new interactions once titrated in the solution; and (c) micellization $\left(\Delta H_{\text {mic }}\right)$ - when the surfactant concentration once more reaches the critical micelle concentration $(\mathrm{cmc})\left(0.11 \mathrm{mmol} \mathrm{L}^{-1}\right)$. This process can be summarized by the following equation:

$\Delta H_{\text {obs }}=\Delta H_{\text {demic }}+\Delta H_{\text {dil }}+\Delta H_{\text {mic }} \quad$ Eq. 1

The difference in enthalpy change between the two horizontal parts of the 2 -shaped curve (Figure 1), is equal to $\Delta H_{\text {mic }}\left(-2.5 \mathrm{~kJ} \mathrm{~mol}^{-1}\right)$. From the titration of surfactant in the HA solution $\left(\Delta H_{\mathrm{obs}}\right)$, there is one more process that produces measurable enthalpy change besides the processes cited above - the interaction of surfactant with $\mathrm{HA}\left(\Delta H_{\mathrm{int}}\right)$.

$\Delta H_{\text {obs }}=\Delta H_{\text {demic }}+\Delta H_{\text {dil }}+\Delta H_{\text {mic }}+\Delta H_{\text {int }}$

Eq. 2

As the only difference between the curves in figure 1 is the presence of HA, CPC clearly interacts with $\mathrm{HA}$. This HA-CPC interaction has also been shown by potentiometric measurements (Koopal et al., 2004).

At low surfactant concentrations (or small surfactant-HA ratios, $R_{\mathrm{s} / \mathrm{ha}}$ ), individual surfactant molecules adsorb along the HA, which is characterized by a critical aggregation concentration (cac). At intermediate $\mathrm{R}_{\mathrm{s} / \mathrm{ha}}$ values, a new process makes $\Delta H_{\mathrm{obs}}$ become less endothermic, suggesting that surfactant monomers aggregate close to the HA structure. After HA saturation (saturation concentration, $C_{2}$ ), further addition of surfactant (increase in $R_{\mathrm{s} / \mathrm{ha}}$ ) promotes micelle formation in the bulk solution (Niemiec and Loh, 2007). Previous studies, using other surfactant molecule interaction systems, have corroborated the molecular processes described above, including surface tension measurements (Peron et al., 2008), conductivity (Nichifor et al., 2008), dialysis (Mylonas et al., 1999), viscosity (Lof et al., 2009), dye solubilization (Dubin et al., 1992), microcalorimetry (Lof et al., 2007), and scattering techniques (Dai and Tam, 2006). The topic has also been studied in several book chapters (Goddard and Anathapadmanabhan, 1993) and review articles (Tam and Wyn-Jones, 2006). Usually, the beginning of the curves (titration in pure solution and in HA containing solution) is the same, and the point where they start to differentiate (cac) is reached after a couple of injections (Barbosa et al., 2010). But since both curves here (in HA solution and in pure buffer solution; Figure 1) are different at the very beginning of titration, we choose to attribute cac to the CPC concentration reached after the first injection $\left(0.055 \mathrm{mmol} \mathrm{L}^{-1}\right)$. In so doing, we are following the protocols for cac determination (the point where curves start to differentiate), but it should be noted that the real cac is probably much smaller than the assigned one. To determine real $c a c$ for a system like this, titrations with very low surfactant concentrations should be tried. 
The first part of the HA-surfactant interaction curve shows an exothermic pattern and that the heat released decreases with each injection. The exothermic reaction proceeds until exothermic heat ceases $\left(0.32 \mathrm{mmol} \mathrm{L}^{-1}\right.$ of $\left.\mathrm{CPC}\right)$, and the curve acquires an endothermic pattern. This endothermic heat reaches a high point and starts to decrease as well, until the point where both curves cross again and remain similar. The intersection of both curves indicates the point where $\mathrm{HA}$ is saturated with surfactant monomers $\left(C_{2}=0.81 \mathrm{mmol} \mathrm{L}^{-1}\right)$ and free surfactant micelles start to form in the HA solution. At this point, there is no more HA-surfactant interaction and, thus, the curves overlap. In comparison, in a study on PEO-SDS (poly(ethylene oxide)-sodium dodecyl sulphate) interaction, cac was found to be equal to $3.6 \mathrm{mmol} \mathrm{L}^{-1}$ of SDS. PEO was saturated by SDS at a total concentration of $17.5 \mathrm{mmol} \mathrm{L}^{-1}$ (Barbosa et al., 2010). This result shows that the presence of charge on the HA particles makes the HA-surfactant interaction stronger than the PEO-SDS interaction, demonstrating a significant contribution of electrostatic energy to the HA-surfactant interaction.

In order to isolate the enthalpy changes related to HA-surfactant interactions (Figure 2), we must subtract the titration curve in the HA solution ( $\Delta H_{\text {obs }}$, equation 2) from the dilution curve in the pure buffer solution $\left(\Delta H_{\text {mic }}\right.$, equation 1$)$ at each surfactant concentration (curves shown in Figure 1), according to the equation shown below:

$\Delta H_{\text {obs }}-\Delta H_{\text {mic }}=\Delta H_{\text {ap-int }}$

Eq. 3

This allows evaluation of the differential apparent enthalpy change for the HA-surfactant interactions $\left(\Delta H_{\text {ap-int }}\right.$, figure 2$)$. Unfortunately, as the extent of binding (amount of surfactant adsorbed) is not known, we cannot calculate the exact molar enthalpy change of interaction, only the apparent molar enthalpy change $\left(\Delta H_{\text {ap-int }}\right)$. However, the features of the $\Delta H_{\text {ap-int }}$ curve give qualitative information about the progress of aggregation with increasing surfactant concentration (Barbosa et al., 2010).

By using ITC to investigate HA-surfactant interactions, it is possible to obtain four important parameters that characterize these interactions, namely (i) the critical aggregation concentration value (cac), (ii) the saturation concentration $\left(C_{2}\right)$, (iii) the integral enthalpy change for aggregate formation $\left[\Delta H_{\text {agg }}\right.$ (int)], and (iv) the number of moles of bound surfactant per HA mass. In the absence of isothermal binding data of CPC to HA, we can calculate the integral enthalpy change for aggregate formation, $\Delta H_{\text {agg }}$ (int). It expresses the enthalpy change of the aggregation of one mole of surfactant into HA, from the first injection up to $C_{2}$. Following Olofsson and Loh (2009) for the $\Delta H_{\text {agg }}$ (int) calculation, we assumed that $C_{2}$ had been reached after $Y$ injections of concentrated surfactant solution (each injection added $n^{\text {inj }}$ moles of surfactant) to

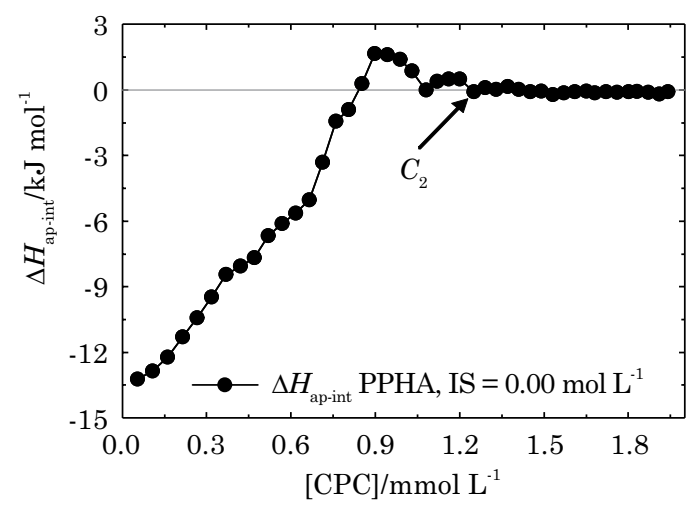

Figure 2. Apparent molar enthalpy change $\left(\Delta H_{\text {ap-int }}\right)$ of interaction between Pahokee peat humic acid (PPHA) and hexadecylpyridinium chloride monohydrate (CPC) surfactant in carbonate buffer at $25^{\circ} \mathrm{C}$ and $0.00 \mathrm{~mol} \mathrm{~L}^{-1}$ ionic strength (IS).

give a total volume of $V_{Y}$. At $C_{2}$, we added a total surfactant equal to $Y n^{\text {inj }}$, but of this total, $V_{Y}[\mathrm{cmc}]$ moles do not interact with HA. Naturally, the total energy measured, $\sum \mathrm{q}_{\mathrm{obs}}$, should be discounted by the energy of demicellization and dilution, $Y q_{\text {demic }}$ + dil. Mathematically, $\Delta H_{\text {agg }}$ (int) is calculated as follows and a summary of all these HA-surfactant parameters is presented in table 1 .

$\Delta H_{\text {agg }}($ int $)=\left(\frac{\sum q_{\text {obs }}-Y q_{\text {demic }+ \text { dil }}}{Y n^{\text {inj }}-V_{\mathrm{y}}[c m c]}\right)$

Eq. 4

Comparing the binding of surfactant on HA at zero ionic strength (IS $=0)$, the three HA surface areas were saturated with surfactant at similar concentration $\left(C_{2}\right)$, with similar energy being released to the system $\left(\Delta H_{\text {agg }}(\right.$ int $\left.)\right)$, and with a similar amount of CPC binding to the HA structure (Table 1). However, with ionic strength higher than 0.00 (from 0.05 to 0.30 ), $C_{2}$ and the amount of CPC binding to the HA decreased for the ESHA, being rather constant for IS equal to $0.05,0.10$, and $0.30 \mathrm{~mol} \mathrm{~L}^{-1}$. One parameter that changed continuously was the $\left(\Delta H_{\text {agg }}(\right.$ int $\left.)\right)$, which became gradually less negative (exothermic) with increasing IS. This shows that even though the extent of binding might not change at higher IS, the nature of the binding is different for each IS studied. In other words, the driving force of the interaction changes from a highly enthalpic process at low IS to a stronger entropic process at higher IS. And even for the PPHA, where the changes in $C_{2}$ or extent of binding do not occur with increasing IS, the change in the $\left(\Delta H_{\text {agg }}(\right.$ int $\left.)\right)$ follows the same pattern.

It may be seen that cationic surfactants strongly bind to the HA structure, especially at $\mathrm{pH} 10$, which is well above the HA point of zero charge ( $\mathrm{pH} 2-2.5)$ (Figure 2). At the first injection, $-13.2 \mathrm{~kJ} \mathrm{~mol}^{-1}$ of heat 
were released from the HA-surfactant interaction. At the second injection, the heat released was -12.9 $\mathrm{kJ} \mathrm{mol}{ }^{-1}$, lower than the first injection. Because the amount of heat released decreases, we are able to discern valuable information regarding HA structure. The heat released is lower with each injection, which shows that the surfactant monomers injected each time are binding to different sites in the HA structure and that this binding is non-cooperative ( $\Delta H$ does not change abruptly). The different binding sites that surfactants encounter at each concentration are probably due to the many different functional groups found in humic substances. If, instead of the pattern seen in figure 2 , a straight line parallel to the " $\mathrm{x}$ " axis was found, it would mean that surfactants were encountering the same type of binding site each time.

As injections proceed, the heat released keeps decreasing until a point where the curve ceases to be exothermic and acquires an endothermic pattern, reaching a maximum $\Delta H_{\text {ap-int }}$ of $1.7 \mathrm{~kJ} \mathrm{~mol}^{-1}$ (Figure 2). At this point, it is assumed that all the negatively charged sites in the HA structure are bonded and that HA-surfactant interaction is now mainly hydrophobically driven, until the point where HA saturates $\left(C_{2}=1.16 \mathrm{mmol} \mathrm{L}^{-1}\right)$ and no more enthalpy change is measured in the titration. The change from an exothermic to an endothermic pattern of the curve can be understood according to the following analysis:

$$
\begin{aligned}
& \Delta H_{\text {ap-int }}=\Delta H_{\text {surf-sol }}+\Delta H_{\text {HA-sol }}+\Delta H_{\text {HA-surf }} \\
& \left|\Delta H_{\text {surf-sol }}+\Delta H_{\text {HA-sol }}\right|<\left|\Delta H_{\text {HA-surf }}\right| \\
& \left|\Delta H_{\text {surf-sol }}+\Delta H_{\text {HA-sol }}\right|>\left|\Delta H_{\text {HA-surf }}\right|
\end{aligned}
$$

where $\Delta H_{\text {ap-int }}$ is the apparent interaction enthalpy change, $\Delta H_{\text {surf-sol }}$ is the enthalpy change due to the interactions between surfactant and solvent molecules, $\Delta H_{\mathrm{HA}-\mathrm{sol}}$ is the enthalpy change due to the interactions between HA and solvent molecules, and $\Delta H_{\mathrm{HA} \text {-surf }}$ is the enthalpy change due to the interactions between HA and surfactant molecules.

The first two components of equation $5\left(\Delta H_{\text {surf-sol }}\right.$ and $\Delta H_{\text {HA-sol }}$, which are due to the desolvation of both surfactant and HA, are always endothermic, while the last component ( $\left.\Delta H_{\mathrm{HA}-\text { surf }}\right)$ is due to the HA-surfactant interaction and contributes negatively to the enthalpy change (exothermic). The $\Delta H_{\mathrm{HA} \text {-surf }}$ that occurs here can occur due to electrostatic, covalent, hydrogen bond, van der Waals, and hydrophobic interactions. Because the first part of the curve shows an exothermic character (Figure 2), the exothermic component $\left(\Delta H_{\text {HA-surf }}\right)$ of equation 5 must overcome the other two endothermic components (Equation 6). We attribute this strong HA-surfactant interaction to an electrostatic interaction between the negatively charged groups in the HA and the positively charged heads of the surfactants. When the curve starts to display the endothermic pattern, it means that the exothermic component $\left(\Delta H_{\text {HA-surf }}\right)$ is no longer too strong and the other two have overcome it (Equation 7). At this point we assume that HA still interacts with the surfactant, but now the interaction is mainly hydrophobically driven. Hydrophobic force is a type of entropic force that comes from the entropy of the network of water molecules (interaction among them); thus, it does not cause great enthalpy changes. These favorable entropy changes due to hydrophobic interactions happen because of an increase in solvent entropy from burial of hydrophobic groups and release of water upon binding, as well as minimal loss of conformational degrees of freedom.

The amphiphilic nature of humic substances and their effects on water surface tension are well established. For that reason, humic substances were thought to be structured as an aggregation of smaller molecules in a micelle-like structure. Wershaw (1993) made an early proposal of the "Membrane-micelle humus model" and Piccolo et al. (1996) claimed to be the first showing direct evidence of the micelle-like or aggregate model of humic substances. After that, new studies continued to support the idea of the supramolecular model of humic substances, which depicts them as a self-assembling association of relatively small heterogeneous molecules held together by weak forces (Conte and Piccolo, 1999; Piccolo et al., 1999; Piccolo, 2001). Currently, the most accepted model maintains the supramolecular idea and, based on NMR spectroscopy, shows that the supramolecular structure is made up of known biochemical compounds such as lignin fragments, alcohols, aliphatic acids, ethers, esters, polysaccharides, polypeptides, and many others, and that metal cations play an important role in their association (Simpson et al., 2002). These authors also pointed out that this supramolecular structure varies according to material of origin and extraction method.

Even though this supramolecular arrangement is probably the way humic substances behave in the environment, our results suggest that there is a core structure for the HA molecule that would not disaggregate (or collapse) from the simple presence of organic acids, for example (Varga et al., 2000). According to our results, it seems that there is some sort of a basic HA structure (HA core) that does not go through any division or conformational change when undergoing an interaction. This is because the $\Delta H_{\text {ap-int }}$ vs [CPC] curve is monotone, without any change in concavity (Figure 2). If the HA structure were undergoing any division or conformational changes, as is believed, peaks and valleys would be seen as features of the curve (Kun et al., 2009; Pires et al., 2011). The curve would show great $\Delta H$ changes due to the occurrence of changes in entropy because of the new parts of the HA 
structure exposed to the solution and exothermic heat due to the aggregation of surfactants to new adsorption sites. As most of the techniques used to build this supramolecular model require solutions with relatively high HS concentration, what researchers named HA supramolecular structure could be just an aggregation (micelle-like) of the true basic structure of HA, as shown by Šmejkalová and Piccolo (2007) and Lam and Simpson (2009). They showed that as HA concentration increases, a noticeable shift in distribution occurs, from smaller to larger components, indicating self-association of humic molecules. Thus, the relatively high HS concentrations required for chromatographic and spectroscopic experiments explain much of the variation related to the structure, size, and behavior of humic substances found so far.

The decomposition process that leads to the formation of humic substances differs according to environmental characteristics. There is great importance of biotic factors in this process in tropical ecosystems, while unique factors affect decomposition in arid and semi-arid ecosystems, including abiotic controls such as photodegradation (Austin and Vivanco, 2006). The literature frequently indicates that humic substances from different origins and/or those that went through different formation processes are qualitatively different from each other (Peña-Méndez et al., 2007). Humic substances composition is believed to be related to source, maturity, depositional environment, and degree of degradation (Lu et al., 2000). Although a number of properties are common to various aquatic and terrestrial humic substances, some authors can distinguish their nature and origin by elemental and spectroscopic analysis (Senesi et al., 1989). Studying humic substances isolated from swamp water, soil, peat, and brown coal by means of elemental composition, ${ }^{13} \mathrm{C}$ NMR, and Py-GC/MS, Lu et al. (2000) concluded that they show similar chemical composition but different structures. In order to determine how different the basic structure of different HA could be in terms of a molecular surfactant probe, we chose HA from three distinct sources (soil, peat, and river) and performed a microcalorimetric study of the HA-surfactant interaction for each one of them (Figure 3). According to the International Humic Substances Society, the chemical properties of these three HA are fairly different in terms of elemental composition, stable isotope ratios, amino acid composition, carbohydrate composition, and functional groups. But the features of the curves of these three humic acids (Figure 3) suggest that, despite the differences regarding their origin or formation, they seem to share a common basic structure. Perhaps PPHA has more hydrophobic sites than ESHA and SRHA due to its higher endothermic peak; yet the similarity of the curves suggests that they share a common basic structure

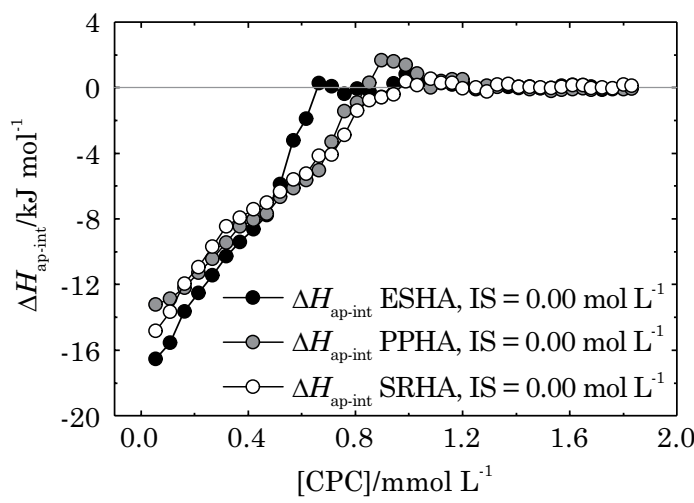

Figure 3. Apparent molar enthalpy change $\left(\Delta H_{\text {ap-int }}\right)$ of the interaction between Elliott soil, Pahokee peat, and Suwannee river humic acids (ESHA, PPHA, and SRHA) and hexadecylpyridinium chloride monohydrate (CPC) surfactant in carbonate buffer at $25{ }^{\circ} \mathrm{C}$ and $0.0 \mathrm{~mol} \mathrm{~L}^{-1}$ ionic strength (IS).

(Figure 3). Corroborating that, they also showed very similar $C_{2}, \Delta H_{\mathrm{agg}}$ (int), and the extent of binding of CPC at $0.00 \mathrm{~mol} \mathrm{~L}^{-1}$ IS (Table 1).

But even though figure 3 shows that different HA share a common basic structure, it also shows that the binding sites are different among them, with different heat being released at each surfactant injection for all three HA. Instead, if the injection points overlap each other, this indicates that there is no difference among the binding sites for the different HA. The interaction of these three HA from different sources with CPC showed a strong interaction at very small amounts of surfactants. For the first injection of surfactant in HA solutions, HA-surfactant interaction released 16.6, -14.8, and $-13.2 \mathrm{~kJ} \mathrm{~mol}^{-1}$, for soil (ESHA), river (SRHA), and peat (PPHA) HA, respectively. As surfactant concentration increases, the different amounts of heat released continue to show differences in the binding sites. These differences in the heat released at each injection allow us to differentiate HA through the ITC technique and are probably due to the great variety of functional groups present in the structure of those HA. It is notable that the features of the titration curves indicate that the interaction of surfactants to the HA structure occurs as monolayers.

As already mentioned, a variety of intermolecular interactions could be the source of the enthalpy change due to the HA-surfactant interaction $\left(\Delta H_{\text {HA-surf }}\right)$. In order to evaluate the importance of electrostatic interaction on $\Delta H_{\mathrm{HA} \text {-surf }}$, we performed the same interaction studies cited above in solutions with increasing ionic strength (IS). Negatively charged HA in solution will attract cations and repel anions. That way, a concentrated layer of cations is formed around them. Assuming 
that these cations do not adsorb onto the surface, they are denoted counterions and represent the diffuse double layer (DDL). The thickness of this double layer is such that it contains a sufficient number of counterions to neutralize the surface charge because the system must be electrically neutral. The electrical potential at the shear surface is defined as the zeta potential (ろ), and this is the value that is typically used to characterize the electrical properties of the surface. Thus, as IS (ion bulk concentration) increases, the thickness of the DDL decreases because $\zeta$ decreases and less volume is required to contain enough counterions to neutralize the surface charge. In other words, increasing IS shields the negative charges of HA in solution. So, since the increase in IS leads to a decrease in $\zeta$ (it could also be an increase, depending on whether $\zeta$ is positive or negative because $\zeta$ draws closer to zero with increasing IS, which represents compression of the DDL), if the nature of HA-surfactant interaction is electrostatic, the increase in the IS in a solution would cause the heat released from this interaction to decrease, allowing the main type of interaction that is occurring to be pinpointed (Tipping, 2005).

The increase in the IS of the solution led to a drastic reduction in the heat released from the HA-surfactant interaction (Figure 4), confirming that the binding of surfactants to HA has an important contribution from electrostatic interaction. The $\Delta H_{\text {ap-int }}$ for the binding of surfactant onto ESHA at the first injection was $-16.5,-9.2,-6.4$, and $-2.8 \mathrm{~kJ} \mathrm{~mol}^{-1}$ for $0.00,0.05,0.10$, and $0.30 \mathrm{~mol} \mathrm{~L}^{-1}$ IS. For PPHA these values were $-13.2,-9.0$, and $-7.2 \mathrm{~kJ} \mathrm{~mol}^{-1}$ for $0.00,0.05$, and $0.10 \mathrm{~mol} \mathrm{~L}^{-1} \mathrm{IS}$. Even though the HA amphiphile structure allows the HA to interact both hydrophobically and electrostatically in the environment, at low ionic strengths (IS $=0$ ), the hydrophobicity of HA does not play an important role and the interaction is basically electrostatically driven (Figure 4). But in an increasingly IS environment, hydrophobic interaction becomes more and more important, as can be seen by the increase in the endothermic part of the curves (Figure 4). At higher IS hydrophobic force plays an important role in HA-surfactant interaction. This can also be seen by the decrease in $\Delta H_{\text {agg }}$ (int) with the increase in IS (Table 1 ). The $\Delta H_{\text {agg }}$ (int) of the HA-surfactant interaction of ESHA went from $-8.76 \mathrm{~kJ} \mathrm{~mol}^{-1}$ at $0.00 \mathrm{~mol} \mathrm{~L}^{-1} \mathrm{IS}$ to $-0.19 \mathrm{~kJ} \mathrm{~mol}^{-1}$ at $0.30 \mathrm{~mol} \mathrm{~L}^{-1} \mathrm{IS}$. This difference confirms the change from the electrostatic nature of the interaction at low IS to the hydrophobic nature at high IS. But even though hydrophobic forces play an important role in the interaction at high IS, the negative $\Delta H_{\text {agg }}$ (int) of $0.19 \mathrm{~kJ} \mathrm{~mol}^{-1}$ tells us that the interaction as a whole still shows an exothermic pattern, i.e., it is not only hydrophobic.

Another interesting thing to notice from these results is the change in $C_{2}$ and in the extent of binding with increasing IS (Table 1). While $C_{2}$ and the extent of binding do not change for PPHA with the increase in IS, they do change for ESHA, becoming smaller with the increase in IS. This means that for ESHA, the increase in IS is not just shielding the HA charged sites, changing the nature of the interaction, but is also diminishing the extent of the interaction. So, the use of solutions with different IS also proved to be useful in the task of differentiating HA. In addition to changes in $C_{2}$ and the extent of binding, changes in the heat involved in the titration of each HA behave differently with the increase in IS. For ESHA, the heat released at the first injection decreased 44.2 and $61.2 \%$ when IS was increased to 0.05 and $0.10 \mathrm{~mol} \mathrm{~L}^{-1}$, respectively, while for PPHA, the heat released decreased 31.8 and $45.4 \%$ after the IS was increased to 0.05 and $0.10 \mathrm{~mol} \mathrm{~L}^{-1}$, respectively. (a)

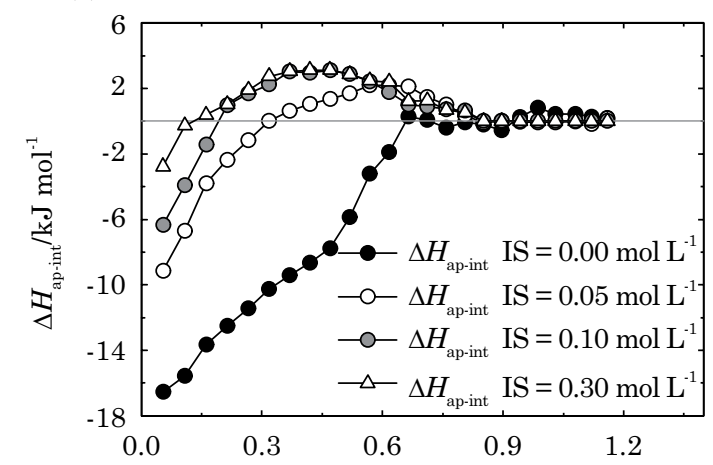

(b)

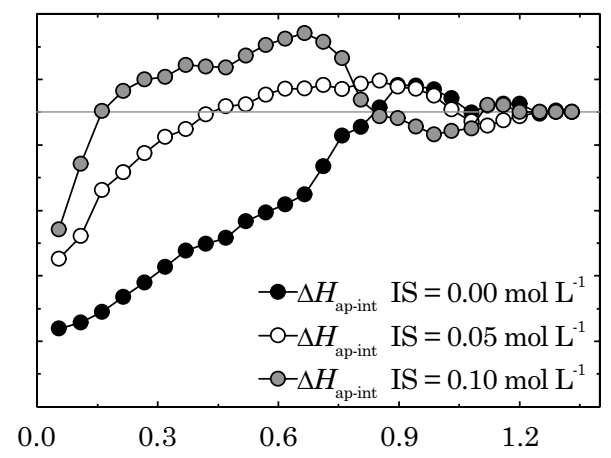

$[\mathrm{CPC}] / \mathrm{mmol} \mathrm{L}^{-1}$

Figure 4. Apparent molar enthalpy change ( $\left.\Delta H_{\text {ap-int }}\right)$ of the interaction between Elliott soil (a) and Pahokee peat (b) humic acids (ESHA and PPHA) and hexadecylpyridinium chloride monohydrate (CPC) surfactant in carbonate buffer at $25^{\circ} \mathrm{C}$ and increasing ionic strength (IS). 


\section{CONCLUSIONS}

On the opposite of what current models say about humic substances, our results suggest that humic acids seem to show a common basic structure, which is rather stable in the environment. And even though humic acids from different origins have different functional groups, this basic structure seem to be present in all humic acids studied here (soil, peat, and river sources).

Due to the presence of electrical charge in both humic acids and the surfactants used in this work, our results show that HA-surfactant interaction is mainly electrostatic at low ionic strengt. However, as IS increases this interaction shifts from electrostatic to hydrophobic, keeping the adsorption capacity of humic acids fairly constant.

\section{ACKNOWLEDGMENTS}

We would like to thank the Brazilian agencies $\mathrm{CNPq}$ (Conselho Nacional de Desenvolvimento Científico e Tecnológico), CAPES (Coordenação de Aperfeiçoamento de Pessoal de Nível Superior), and FAPEMIG (Fundação de Amparo à Pesquisa do Estado de Minas Gerais) for financial support. We are also thankful to Dr. Robert B. Jackson for revising our manuscript.

\section{REFERENCES}

Amundson R. The carbon budget in soils. Ann Rev Earth Plant Sci. 2001;29:535-62.

Austin AT, Vivanco L. Plant litter decomposition in a semi-arid ecosystem controlled by photodegradation. Nature. 2006;442:555-8.

Barbosa AM, Santos IJB, Ferreira GMD, Hespanhol da Silva MDC, Teixeira ALVNDC, Silva LHM. Microcalorimetric and SAXS determination of PEO-SDS interactions: the effect of cosolutes formed by ions. J Phys Chem B. 2010;114:11967-74.

Christensen JJ, Hansen LD, Izatt RM. Handbook of proton ionization heats and related thermodynamic quantities. New York: John Wiley \& Sons; 1976.

Conte P, Piccolo A. Conformational arrangement of dissolved humic substances. Influence of solution composition on association of humic molecules. Environ Sci Technol. 1999;33:1682-90.

Dai S, Tam KC. Effect of cosolvents on the binding interaction between poly(ethylene oxide) and sodium dodecyl sulfate. J Phys Chem B. 2006;110:20794-800.

Dubin PL, Gruber JH, Xia J, Zhang H. The effect of cations on the interaction between dodecylsulfate micelles and poly(ethyleneoxide). J Colloid Interf Sci. 1992;148:35-41.

Gamboa C, Olea AF. Association of cationic surfactants to humic acid: effect on the surface activity. Colloids Surfaces Physicochem Eng Aspects. 2006;278:241-5.
Goddard ED, Anathapadmanabhan KP. Interaction of surfactants with polymer and proteins. New York: CRC Press; 1993.

Kickuth R. Huminstoffe - ihre chemie und ökochemie. Chem Labor Betried. 1972;23:481-6.

Koopal LK, Goloub TP, Davis TA. Binding of ionic surfactants to purified humic acid. J Colloid Interf Sci. 2004;275:360-7.

Kucerík J, Kovár J, Pekar M. Thermoanalytical investigation of lignite humic acids fractions. J Therm Anal Calorim. 2004;76:55-65.

Kun R, Szekeres M, Dékány I. Isothermal titration calorimetric studies of the $\mathrm{pH}$ induced conformational changes of bovine serum albumin. J Therm Anal Calorim. 2009;96:1009-17.

Lam B, Simpson AJ. Investigating aggregation in Suwannee River, USA, dissolved organic matter using diffusion-ordered nuclear magnetic resonance spectroscopy. Environ Toxicol Chem. 2009;28:931-9.

Lof D, Schillen K, Loh W, Olofsson G. A calorimetry and light scattering study of the formation and shape transition of mixed micelles of EO20PO68EO20 triblock copolymer (P123) and nonionic surfactant (C12EO6). J Phys Chem B. 2007;111:5911-20.

Lof D, Tomsic M, Glatter O, Fritz-Popovski G, Schillen K. Structural characterization of nonionic mixed micelles formed by C12EO6 surfactant and P123 triblock copolymer. J Phys Chem B. $2009 ; 113: 5478-86$.

Lu XQ, Hanna JV, Johnson WD. Source indicators of humic substances: an elemental composition, solid state ${ }^{13} \mathrm{C}$ CP/MAS NMR and Py-GC/MS Study. Appl Geochem. 2000;15:1019-33.

Mylonas Y, Staikos G, Lianos P. Investigation of the poly (N-isopropylacrylamide)-sodium dodecyl sulfate complexation with viscosity, dialysis, and time-resolved fluorescence-quenching measurements. Langmuir. 1999;15:7172-5.

Nichifor M, Bastos M, Lopes S, Lopes A. Characterization of aggregates formed by hydrophobically modified cationic dextran and sodium alkyl sulfates in salt-free aqueous solutions. J Phys Chem B. 2008;112:15554-61.

Niemiec A, Loh W. Interaction of ethylene oxide-propylene oxide copolymers with ionic surfactants studied by calorimetry: Random versus block copolymers. J Phys Chem B. $2007 ; 112: 727-33$.

O’Brien R, Ladbury JE, Chowdhry BZ. Isothermal titration calorimetry of biomolecules. In: Harding SE, Chowdhry BZ, editors. Protein-ligand interactions: Hydrodynamics and calorimetry. Oxford: Oxford University Press; 2001. p.263-86.

Olofsson G, Loh W. On the use of titration calorimetry to study the association of surfactants in aqueous solutions. J Braz Chem Soc. 2009;20:577-93.

Peña-Méndez EM, Novotna K, Gajdosova D, Gonzalez V, Havel J. Characterization of humic substances of different origin by means of mass spectrometry and neural networks. Chemosphere. 2007;68:2047-53.

Peron N, Campbell RA, Nylander T, Vareikis A, Makuska R, Gilanyi T, Meszaros RB. Competitive adsorption of neutral comb polymers and sodium dodecyl sulfate at the air/water interface. J Phys Chem B. 2008;112:7410-9.

Piccolo A, Conte P, Cozzolino A. Effects of mineral and monocarboxylic acids on the molecular association of dissolved humic substances. Eur J Soil Sci. 1999;50:687-94. 
Piccolo A, Nardi S, Concheri G. Micelle-1ike conformation of humic substances as revealed by size exclusion chromatography. Chemosphere. 1996;33:595-602.

Piccolo A. The supramolecular structure of humic substances. Soil Sci. 2001;166:810-32.

Pires ACS, Soares NFF, Silva LHM, Silva MCH, Almeida MV, Le Hyaric M, Andrade NJ, Soares RF, Mageste AB, Reis SG. A colorimetric biosensor for the detection of foodborne bacteria. Sensors Actuat B Chem. 2011;153:17-23.

Roger GM, Durand-Vidal S, Bernard O, Mériguet G, Altmann S, Turq P. Characterization of humic substances and polyacrylic acid: A high precision conductimetry study. Colloid Surface A. 2010;356:51-7.

Senesi N, Miano TM, Provenzano MR, Brunetti G. Spectroscopic and compositional comparative characterization of I.H.S.S. reference and standard fulvic and humic acids of various origin. Sci Total Environ. 1989;81-82:143-56.

Simpson A, Kingery W, Hayes M, Spraul M, Humpfer E, Dvortsak P, Kerssebaum R, Godejohann M, Hofmann M. Molecular structures and associations of humic substances in the terrestrial environment. Naturwissenschaften. 2002;89:84-8.

Šmejkalová D, Piccolo A. Aggregation and disaggregation of humic supramolecular assemblies by NMR diffusion ordered spectroscopy (DOSY-NMR). Environ Sci Technol. 2007;42:699-706.

Tam KC, Wyn-Jones E. Insights on polymer surfactant complex structures during the binding of surfactants to polymers as measured by equilibrium and structural techniques. Chem Soc Rev. 2006;35:693-709.

Tipping E. Cation binding by humic substances. Cambridge environmental chemistry series -11 . Cambridge: Cambridge University Press; 2005.

Varga B, Kiss G, Galambos I, Gelencser A, Hlavay J, Krivácsy Z. Secondary structure of humic acids. Can micelle-like conformation be proved by aqueous size exclusion chromatography? Environ Sci Technol. 2000;34:3303-6.

Velázquez-Campoy A, Ohtaka H, Nezami A, Muzammil S, Freire E. Isothermal titration calorimetry. New York: John Wiley \& Sons; 2004. p.1-24.

Wershaw RL. Model for humus in soils and sediments. Environ Sci Technol. 1993;27:814-6.

Wershaw RL. Molecular aggregation of humic substances. Soil Sci. 1999;164:803-13.

Zhang Y, Du J, Zhang F, Yu Y, Zhang J. Chemical characterization of humic substances isolated from mangrove swamp sediments: The Qinglan area of Hainan Island, China. Estuar. Coast. Shelf Sci. 2011;92:220-7. 